\title{
ON TELOS \\ AND GENETIC \\ MANIPULATION
}

BERNARD ROLLIN

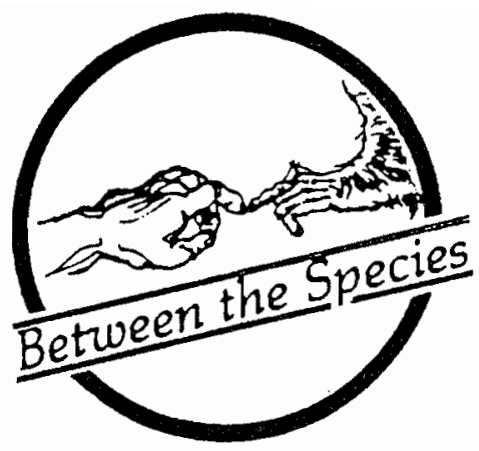

Colorado State University

In 1981, in my Animal Rights and Human Morality, [1] I gained the perhaps dubious distinction of attempting to rouse the Aristotelian concept of telos from the dogmatic slumber in which it had long lain, attended to only by scholastic philosophers. It appeared to me (and still does) that the notion of telos provides a sound basis from which to deduce the rights of animals of different species, even as human rights have been based in plausible hypotheses about human nature. In so far as different kinds of animals are built in different sorts of ways for different sorts of things and in so far as these differences are rooted in biological, genetically based, empirically ascertainable, environmentally expressed "blueprints," I saw nothing problematic about the concept of telos that would not also trouble both the ordinary and the scientific notions of species, or perhaps, sub-species, depending upon what one takes as a basic unit of classification. Both common sense and modern biology, after all, note that "fish gotta swim and birds gotta fly," as Professor Harlan Miller put it in reviewing my book. Furthermore, as I argued later, once one had leaped positivistic and behavioristic hurdles about animal consciousness, one could generate a notion of happiness and whappiness for different sorts of animals in terms of whether or not they were in a position to fulfill their telos, or to engage in those activities whose infringement or thwarting matter most to them. [2]

It is perhaps not surprising, though certainly disappointing, that this concept should be radically misunderstood by significant segments of both sides of the debate on genetic engineering of agricultural animals. While my own position on the relevance of telos to genetic engineering is laid out fully in a forthcoming article, a version of which I gave as a keynote speech to the First International Conference on Genetic
Engineering of Agricultural Animals in September, 1985, at the University of California, Davis, [3] I should like briefly to conment on what I take to be serious misconstructions of the concept, at least as I use it.

The scientists, quoted by Dr. Fox, who see the concept of telos as "mystical" are seriously in error. Their view is as much off the mark and in the same way as those scientists earlier this century who sought to eliminate teleological explanation from biology. Given the mechanistic bias of modern biology, as well as the unfortunate tendency of many earlier thinkers to equate teleology with consciously designed purpose and this with Divine Plan, one can understand such reservations. After all, the suggestion that lakes freeze from the top down in order to protect the fish is indeed mystical, religious ideology. On the other hand, those who deny that adrenalin is released in order to alert the body to fight or flight, or that the immune system exists to fight infection, or that there is a pigness to a pig and a dogmess to a dog bespeak a mischievous, religiously overzealous ideology of their own, equally absurd and dogmatic. Scientists and philosophers like sommerhoff, Wiener, Braithwaite, and Nagel have shown long ago that there is nothing inherently problematic about teleological explanations, and biological sciences as diverse as taxonomy, ethology, evolutionary theory, veterinary medicine, genetics, and so on have presupposed the existence of kinds of animals. To deny ar-

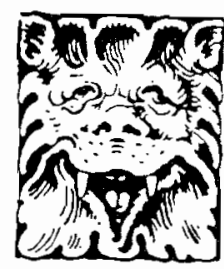

COMMENT 
ticulatable, discoverable, common features among pigs or dogs is surely not good science; in fact, taking such a claim seriously would effectively make all of the above sciences impossible. If we keep fish but not mice in bowls of water, if we heep manure on our plants but not on our cats to help then grow, if we walk our dogs but not our. lichen, we have presupposed differences in telos. None of this is mystical nor requires invoking the Deity; evolution will do.

On the other hand, when Fox asks, "Is not the unique genetic make-up of species-their telos--to be respected and worthy of moral consideration?", he is guilty of a serious ambiguity with great potential for mischief. In my ow writing on animal rights, I have argued that given an animal's telos, it is prima facie wrong to infringe upon it. Critics of genetic engineering, however, sometimes suggest that the telos itself is inviolable, that it is wrong to change it, rather than violate the fundamental animal interests which constitute it. This surely cannot be correct. Suppose that one can change a telos, $T l$, by breeding, natural selection, genetic engineering, or whatever to $\mathrm{T} 2$, so that animals which have the new telos are less prone than their predecessors to certain diseases or injuries or predators. To take a fanciful example, suppose that one changed the genome of a grazing animal forced to live in a limited forage environment, so that it could now photosynthesize its food as well as graze. Unknown environmental considerations aside, and assuming this change had no harmful or painful effects on the animal, surely such a change would not in and of itself be wrong. On my view, then, it is only wrong to change a telos if the individual animals of that sort are likely to be more unhappy or suffer more after the change than before.

In short, then, one cannot argue that because it is wrong to violate the various aspects of a certain animal's telos given the telos, it is therefore wrong to change the telos. This is true only if the change in the telos is likely to engender more unhappiness in the animals, given the environment in which they live, than would have accrued to them before. What respect for telos does is give us a way of measuring the rightness or wrongness of our actions vis a vis the individual animals falling under the telos; it does not tell us that we cannot change the characteristics of the type in question, especially if the animals falling under the new type are less likely to suffer. Given the rules of chess, one cannot move the castle diagonally; that tells us nothing about whether we ought to invent a new game with a new set of rules in which one can so move.

On the other hand, critics like Fox do have a powerful point. Given the human purposes of productivity and efficiency to which genetic engineering (or telos changing) of animals is likely to be aimed, in all probability, such changes in telos are unlikely to make the animals better off. Scientists attempting to engineer oversized animals like chickens are already reporting joint problems, since the joint cannot bear the additional weight. Thus, the engineering of telos for increased size is likely to lead to a new sort of suffering, which would probably be of little concern to producers as long as it didn't impair efficiency. In other words, if the increasing weight gain economically outweighed. the econonic effects (if any) of painful joints, it is likely that this pernicious result to the animal would be ignored. Thus, given the economic basis of animal engineering, it is plausible that one whose concern is the happiness of animals should show healthy skepticism about such telos manipulation, for in fact, it is probably likely to generate more harm than good for the animals. But this is very different from saying that changing telos is in principle wrong. Indeed, if public awareness of and distress over the suffering of animals continues to grow, it is very possible that modification of telos could turn into a powerful tool for alleviating that suffering, rather than just a short cut to further exploitation. For example, one could concentrate on engineering animals which are happy in the environments in which we put them.

\section{Notes}

1. Bernard E. Rollin, Animal Rights and Human Morality (Buffalo: Prometheus Books, 1981).

2. Bernard E. Rollin, "The Care and Use of Swine in Biomedical Research," forthcoming in M. E. Tumbleson, ed., Swine in Biomedical Research (New York: Alan R. Liss, 1986):

3. Bernard E. Rollin, "The Frankenstein Thing," forthcoming in A. Hollaender and $\mathrm{C}$. Wilson, eds., Genetic Engineering of Animals: An Agricultural Perspective (New York: Plenum, 1986). 